
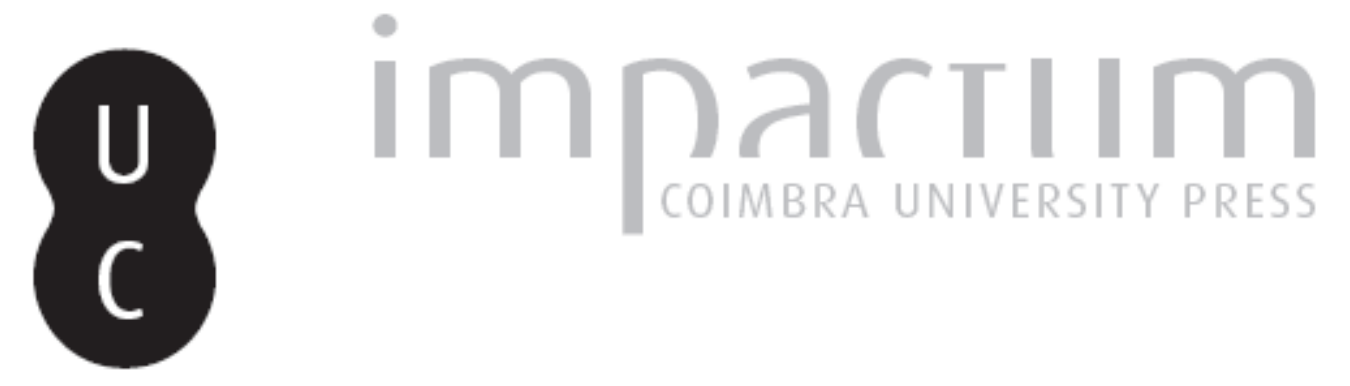

\title{
Algumas peças da villa de Freiria: (Cascais)
}

\section{Autor(es): $\quad$ Cravinho, Graça}

Publicado por: Imprensa da Universidade de Coimbra

URL persistente:

URl:http://hdl.handle.net/10316.2/45495

DOI:

DOI:https://dx.doi.org/10.14195/1647-8657_32_33_21

Accessed : $\quad$ 26-Apr-2023 09:51:00

A navegação consulta e descarregamento dos títulos inseridos nas Bibliotecas Digitais UC Digitalis, UC Pombalina e UC Impactum, pressupõem a aceitação plena e sem reservas dos Termos e Condições de Uso destas Bibliotecas Digitais, disponíveis em https://digitalis.uc.pt/pt-pt/termos.

Conforme exposto nos referidos Termos e Condições de Uso, o descarregamento de títulos de acesso restrito requer uma licença válida de autorização devendo o utilizador aceder ao(s) documento(s) a partir de um endereço de IP da instituição detentora da supramencionada licença.

Ao utilizador é apenas permitido o descarregamento para uso pessoal, pelo que o emprego do(s) título(s) descarregado(s) para outro fim, designadamente comercial, carece de autorização do respetivo autor ou editor da obra.

Na medida em que todas as obras da UC Digitalis se encontram protegidas pelo Código do Direito de Autor e Direitos Conexos e demais legislação aplicável, toda a cópia, parcial ou total, deste documento, nos casos em que é legalmente admitida, deverá conter ou fazer-se acompanhar por este aviso.

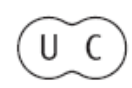




\section{UNIVERSIDADE DE COIMBRA \\ FACULDADE DE LETRAS}

\section{CONIMBRIGA}

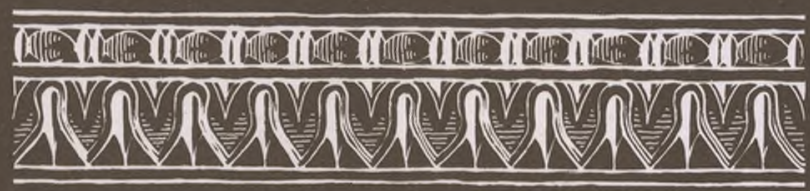

VOLUMES XXXII-XXXIII-1993/94 
GRAÇA CRAVINHO

Assistente convidada da Faculdade de Ciências da Universidade de Lisboa

\author{
ALGUMAS PEÇAS DA VILLA DE FREIRIA (CASCAIS)
}

«Conimbriga» XXXII-XXXIII (1993-1994), p. 333-348

RESUMO: Os materiais da villa de Freiría, pela sua riqueza e diversidade, com-

provam, tal como as estruturas arquitectónicas, a importância e a intensa ocupação que ela teria tido (já no período republicano e, sobretudo, entre os séculos I e IV d. C.) e demonstram, uma vez mais, a profundidade da romanização no concelho de Cascais.

Lamentavelmente, porém, e salvo raríssimas excepções, estão muito fragmentados e/ou desgastados, mercê da intensa actividade agrícola a que o solo esteve sujeito ao longo dos tempos, dada a sua fertilidade, a abundância de água e a amenidade do clima (já que a sua localização num vale a protege dos ventos que sopram entre a terra e o mar).

Estudam-se aqui três pedras de anel, três minimáscaras de terracota e uma lucerna decorada com a representação de Vitória.

SUMMARY: The richness and diversity of the spoil from the "Villa de Freiria" show, as do the architectural structures, the importance and intensive occupation of the villa already by the Republican era and above all between the $1^{\text {st }}$ and $4^{\text {th }}$ centuries A. D., and prove once again the depth of romanizad on in the Cascais region.

Unfortunately, however, and with the rarest exceptions, the spoil is very fragmented and/or worn. This is due to the heavy agricultural activity to which the land has been subjected down the years. Such activity has been due, in its turn, to the fertility of the soil, the abundance of water and the temperate climate: the location of the villa in a valley protects it from the winds which blow between the land and the sea. 
(Página deixada propositadamente em branco) 


\section{ALGUMAS PEÇAS DA VILLA DE FREIRIA (CASCAIS)}

A villa de Freiría situa-se na freguesia de S. Domingos de Rana, concelho de Cascais, num vale entre Outeiro e Polima, com óptimas condições de habitabilidade (abundância de água, solo fértil - de natureza basáltica - e clima ameno) que permitiram uma importante actividade agrícola e pecuária, testemunhada pelas estruturas que, desde 1985, têm sido postas a descoberto (O-

O espólio encontrado é abundante, mas serão apenas as pedras de anel, as terracotas e uma lucerna que constituirão o objecto de estudo deste trabalho.

\section{As pedras de anel}

Encontradas em campanhas de escavação diferentes, todas são inéditas e apresentam diferenças quanto à sua natureza, motivos representados, tamanho e estado de conservação.

1.1. PEDRA N..$^{\circ} 1$ - A de menores dimensões e parcialmente fragmentada na mesa (Fig 1).

(9 Vide: CARDoso, Guilherme, Carta Arqueológica do Concelho de Cascais, Câmara Municipal de Cascais, Cascais, 1991; CARDOSO, Guilherme e ENCARNAÇÃO, José de, "Certezas e Incertezas no Estudo da Villa Romana de Freiria", Arquivo de Cascais, Câmara Municipal de Cascais, Cascais, 1991; CARDOSO, Guilherme e ENCARNAÇ̃̃O, José d', "A villa romana de Freiria e o seu enquadramento rural". Studia Historica - História Antigua, vol. X-XI, Salamanca, 1992-1993, p. 203 a 2171. 


\section{Descrição:}

- Dimensões:

- eixo maior - 9,5 $\mathrm{mm}$

- eixo menor - 7,5 mm

- espessura - cerca de $2,3 \mathrm{~mm}$.

- Forma: oval.

- Mesa: plana, com bordadura convexa, bizelada e polida.

- Base: plana, com bordadura biselada e desgastada (vista à lupa, apresenta-se com estrias), sem polimento posterior.

- Natureza da pedra: a análise feita pelos Serviços Geológicos de Portugal permitiu concluir não se tratar de uma gema, mas sim de uma rocha-talvez o Udito $\left({ }^{2}\right)$.

Constituirá o que arqueólogos ingleses e italianos designam por nicolo?

Tal designação é dada a uma variedade especial de ónix (ou de ágata), de duas camadas, cuja camada inferior é normalmente azul-escuro ou de jaspe negro (e, por vezes, de sardónica escura), não transparente e a camada superior é fina e de cor azul-esbranquiçado.

Tendo começado a ser usados no século I a. C., os nicolos são, na sua imensa maioria, do século II d. C. e permaneceram durante todo o Império - pelo agradável efeito cromático produzido pelo contraste entre a parte central da mesa e a superfície que a rodeia.

De facto, relativamente a esta pedra de Freiría, uma das hipóteses inicialmente aventada foi estarmos perante um ónix. Mas logo foi abandonada porque, nesse caso, seria mais transparente e "zonada" (conforme nos foi dado a observar em exemplares existentes no museu dos Serviços Geológicos de Portugal).

- Cor: azul-leitoso, no campo (superfície gravada) e azul muito escuro, quase negro, na parte que o rodeia.

- Estado de conservação: incompleta.

- Localização: na posse de Guilherme Cardoso.

- Motivo gravado: de difícil identificação, dado o facto de a mesa estar parcialmente fragmentada, reduzindo praticamente a metade a figura. O pouco que consegue divisar-se denota uma gravação um tanto esquemática e, consequentemente, estilizada.

$\left.{ }^{2}\right) \quad$ A impossibilidade de, aquando da análise, poder utilizar-se uma lupa binocular bem como a de poder efectuar-se uma análise destrutiva conduziram a esta indefinição. 
A análise feita aos moldes parece, porém, apontar no sentido de se tratar de uma figura humana caminhando, voltada à direita e com a cabeça coberta por um capacete.

Todavia, o modo como foi trabalhada a parte posterior da figura faz lembrar a técnica utilizada na gravação das asas das figuras aladas.

\section{Comentário:}

O seu estado de conservação torna, assim, extremamente difícil não apenas a identificação do motivo como o estabelecimento de paralelos.

A cabeça, embora numa posição ligeiramente diferente, faz lembrar a de Mercúrio, tal como aparece gravada numa gema de Conimbriga (n. ${ }^{\circ}$ de inventário: 65.571).

Pelo capacete que parece ostentar, poderemos pensar que representa um guerreiro - tema muito frequente em todo o Império. Ou representará uma divindade guerreira? De facto, as representações de divindades são muito frequentes em nicolos.

Exemplares com o mesmo tema (guerreiro ou divindade guerreira), encontrados em Portugal, estão patentes no Museu Nacional de Arqueologia (num dos casos representando a deusa Minerva, num nicolo com ambas as faces igualmente biseladas) e no Museu Monográfico de Conimbriga, já referidos por Mário Cardozo, em 1962 (3).

Miriam Astrue (4) refere também quatro exemplares com este motivo.

O mesmo fazem Marshal $\left(^{5}\right)$ e Gisela Richter $\left({ }^{6}\right)$ relativamente a exemplares existentes no British Museum (Londres) e no Metropolitan Museum of Art (Nova Iorque), respectivamente.

(3) Vide: Cardozo, Mário, "Pedras de anéis romanos encontradas em Portugal", separata da Revista de Guimarães, voi. LXXII, n.os 1-2. Guimarães, 1962 (pedras n.os $1 ; 22 ; 28)$.

$\left(^{4}\right)$ Vide: Astruc, Miriam, "Catálogo Descriptivo de los Entalles Procedentes de Distintos Sítios de la Colonización oriental de la Península”, Memorias de los Museos Arqueológicos Provinciales", XX, 1954 (1958), pp. 118 e 119.

$\left(^{5}\right)$ Vide: Marshall, F. H., Catalogue of the Finger Rings. Greek, Etruscan and Roman in the Department of Antiquities, British Museum, Londres, 1907.

$\left(^{6}\right)$ Vide: Richter, Gisela M. A., Catalogue of Engraved Gems, Greek, Etruscan and Roman Metropolitan Museum of Art - New York, Roma, 1956. 


\section{Datação:}

A sua fragmentação oferece também grandes limitações ao estabelecimento de uma cronologia, dado ser difícil uma análise estilística e temática. Todavia, as dimensões e as duas faces planas poderão permitir-nos enquadrá-la no período tardo-republicano ou, caso se trate efectivamente de um nicolo, ainda nos dois primeiros séculos d. C. $\left.{ }^{7}\right)$.

1.2. PEDRA N..$^{\circ} 2$ - Encontrada em Agosto de 1991, nas imediações do celeiro da villa, está em excelente estado de conservação (Fig. 2).

\section{Descrição:}

- Dimensões:

- eixo maior - $12 \mathrm{~mm}$

- eixo menor - $10 \mathrm{~mm}$

- espessura - $3 \mathrm{~mm}$.

- Forma: oval.

- Mesa: convexa.

- Base: plana, desgastada e posteriormente polida.

- Natureza da pedra: pela análise feita, concluiu-se ser também uma rocha. As hipóteses apontam no sentido de poder tratar-se de um micropórfiro (rocha magmàtica, abundante na Serra de Sintra) ou de serpentinite (rocha siliciosa).

- Cor - acastanhada, com veios claros. Vista sob a luz directa do sol, assume um tom esverdeado.

- Estado de conservação - completa.

- Localização: na posse de Guilherme Cardoso.

- Motivo gravado: biga conduzida por um cocheiro (de perfil), com a cabeça adornada por uma coroa radiada. Uma das mãos segura as rédeas e a outra empunha uma palma, em sinal de vitória. $\mathrm{Na}$ parte inferior do conjunto e prolongando-se para além das patas traseiras dos cavalos (de perfil), vê-se uma linha de solo. As patas dianteiras estão erguidas, em movimento de corrida.

(7) Vide: GraÇA, Maria Antónia, e MACHado, João Saavedra, "Uma Colecção de Pedras Gravadas - Elementos para um Catálogo Geral", Actas do II Congresso Nacional de Arqueologia, vol. II, Coimbra, 1970 p. 381, referem um nicolo, proveniente do "Tesouro da Borralheira", datado de princípios do século III d. C. 


\section{Comentário:}

Estaremos perante a representação de um auriga vencedor?

Tanto relativamente a Portugal como a outros países, não encontrámos qualquer paralelo na representação deste motivo. Motivos mais ou menos semelhantes eram, todavia, já frequentes na ourivesaria e na glíptica etruscas e da Antiga Grécia. Marshall (pp. 7; 15; 198; 239) apresenta-os em quatro anéis, existentes no British Museum:

- biga conduzida por um cocheiro (anel proveniente de Chipre, do séc. VI a. C.): apenas a cabeça do cocheiro, a parte superior dos cavalos (de perfil) e uma parte do carro estão representados;

- biga conduzida por um cocheiro que empunha um aguilhão (anel grego, do século IV a. C.);

- biga conduzida por um cocheiro cujo cabelo é adornado por uma fita, esvoaçando para trás (anel grego, do século IV a. C.);

- biga conduzida por um cocheiro barbado (escaravelho etrusco, de cerca de finais do século VI a. C.).

Pelo mesmo autor é também referida a existência, no mesmo museu, de uma gema romana de cerca do séc. II d. C. e em que a biga é conduzida por uma Vitória alada (p. 243).

Tema semelhante aparece numa gema do Metropolitan Museum of Art, em que a Vitória alada segura uma palma, numa cena sublinhada por uma linha de solo e que Gisela Richter (p. 83) integra cronologicamente no período imperial.

Igualmente está patente no Museo Arqueológico Nacional, de Madrid, em dois exemplares que Raquel Casal Garcia $\left.{ }^{8}\right)$ data do séc. I a. C., ambos ostentando uma Vitória alada.

Aliás, a representação da Vitória na glíptica romana é profusa e derivará, provavelmente, de representações análogas em moedas republicanas do século II a. C. Frequente também é o seu aparecimento em lucernas - caso de uma existente no Museu de Guimarães, em que uma Vitória alada conduz uma biga, segurando na mão direita uma coroa e na esquerda as rédeas $\left({ }^{9}\right)$.

Em nenhum dos exemplos mencionados, porém, o condutor da biga apresenta uma coroa radiada. Coroa radiada aparece, isso sim, na

$\left(^{8}\right)$ Vide: Casal Garcia, Raquel, Colleccion de Glíptica del Museo Arqueológico Nacional (serie de entalles romanos), vols. I e II. Madrid, 1992, pp. 87 e 88.

$\left({ }^{9}\right)$ Vide: AlmeidA, José António Ferreira de, "Introdução ao Estudo das Lucernas Romanas em Portugal”, Arqueólogo Português, n. s., II, Lisboa, 1953, p. 157. 
representação de cocheiros conduzindo quadrigas e identificados com Helios, no seu carro solar. É uma iconografia muito frequente no Baixo Império, que não tem necessariamente um carácter mágico (o que é unicamente assegurado pela existência de palavras mágicas, acompanhando a cena figurada).

Um exemplo de representação deste motivo é-nos apresentado por Raquel Casal Garcia (p. 190), numa gema do Museo Arqueológico Nacional, de Madrid, datada do século III d. C. e com dimensões muito semelhantes às desta de Freiría $(12 \mathrm{x} 10 \mathrm{x} 2 \mathrm{~mm})$, embora com ambas as faces planas. Nela, os cavalos, voltados à esquerda, estão em posição de três quartos, com as patas dianteiras levantadas em sinal de movimento. Sob as patas traseiras, uma linha de solo. Sobressaindo por detrás das cabeças dos cavalos, a figura de Hélios, muito esquematizada e ladeada por dois pequenos Eros. À esquerda do campo, vê-se uma ave olhando os cavalos e, ocupando a parte inferior da gema, um lagarto, visto de cima.

Também Marshall (p. 91) refere um exemplar do British Museum, que igualmente data do séc. Ill d. C.: um anel com um nicolo, em que se representa Hélios com uma coroa radiada e conduzindo uma quadriga para a frente. Sob as patas dianteiras, é igualmente visível uma linha de solo.

Aparecem igualmente quadrigas conduzidas por cocheiros sem atributos especiais e que poderão apenas representar aurigas vencedores. É um tema muito frequente quer em moedas, quer na glíptica, quer até em lucernas - caso de uma referida por Ferreira de Almeida (p. 172), proveniente de Beja e existente no Museu Nacional de Arqueologia.

Em gemas, encontramos um exemplar no Metropolitan Museum of Art, em que um homem, segurando na mão direita as rédeas e na esquerda a palma, conduz uma quadriga a galope. Na parte inferior do campo, no espaço entre as patas dianteiras (erguidas) e as patas traseiras, estão gravadas as letras IPI (em caracteres gregos), cujas formas permitem atribuir-lhe uma datação tardia (Gisela Richter, p. 83).

Outro exemplar, do Museo Arqueológico Nacional, de Madrid, data do período romano - republicano (mais concretamente, do séc. I a. C.) e a sua técnica de gravação lembra as técnicas etruscas a globolo e a sua derivação em pellet (Raquel Casal Garcia, p. 110).

Quadrigas conduzidas por Vitória são também frequentes.

Marshall (p. 10) apresenta um anel grego, proveniente da Magna Grécia e datado de cerca de 400 a. C., em que este tema aparece. 
Gisela Richter (p. 83) refere também uma gema em que a Vitória segura na mão esquerda as rédeas e uma palma e estende a mão direita. Sob a cena, as letras AER e, por cima, a letra T. Apesar de ser uma composição vulgar no período romano, as formas das letras permitem datá-la do I ou do II século d. C.

Todavia, a pedra de Freiría não apresenta uma quadriga mas uma biga. De facto, tanto nas moedas, como nas gemas, como nos mosaicos, os artistas baseavam-se em modelos cuja iconografia nem sempre era inteiramente respeitada.

Estaremos perante uma simplificação do tema de Hélios no seu carro solar?

\section{Dotação:}

A linha de solo que apresenta permite-nos integrá-la cronologicamente no período romano - imperial.

Outros elementos - como a mesa convexa, as pequenas dimensões da pedra (comparativamente às do período republicano e às do século III d. C. em diante) e a perfeição da técnica de gravação - apontam para o estilo classicista (período de Augusto e Júlio-Cláudios). Mas poderemos também estar em presença de uma peça mais tardia, fruto do revivalismo do estilo classicista próprio dos séculos III e IV d. C. Na verdade, há exemplos de entalhes e camafeus que Furtwängler (A. G., III, p. 366) datara da época dos Júlio - Cláudios e hoje atribuíveis àqueles séculos. Aliás, o próprio tema de Hélios - se dele se trata na pedra de anel em causa - é, conforme se viu, muito frequente no Baixo Império.

Tal como relativamente à primeira pedra de anel, o contexto arqueológico nada ajuda à sua datação, uma vez que foi encontrada num estrato em que apareceu também cerâmica campaniforme, cerâmica da Idade do Ferro e cerâmica romana - facto explicável pela intensa actividade agrícola a que o terreno esteve sujeito ao longo dos séculos.

1.3. PEDRA N. ${ }^{\circ} 3$ - Encontrada em Agosto de 1994, é a de maiores dimensões e não apresenta qualquer motivo gravado (Fig. 3).

\section{Descrição:}

\section{- Dimensões:}

- eixo maior - 23,5 mm 
- eixo menor - $19 \mathrm{~mm}$

- espessura - $10 \mathrm{~mm}$.

- Forma: oval

- Mesa: convexa

- Base: ligeiramente convexa

- Natureza da pedra: vidro transparente, levemente irisado e apresentando bolhas na pasta.

- Cor: verde-claro.

- Estado de conservação: praticamente completa, tendo apenas uma ligeira fractura numa das extremidades.

- Localização: na posse de Guilherme Cardoso.

\section{Comentário:}

As pedras de anel em pasta vítrea tornaram-se primeiramente frequentes no período helenístico. Correspondendo a uma época em que a ostentação estava a sobrepôr-se ao bom gosto, várias foram encontradas em Chipre e em Alexandria (que deveria ter sido o centro da sua manufactura).

No período romano, eram igualmente comuns. Na origem de tal profusão, deve estar o facto de as gemas serem provenientes de lugares muito distantes do Império, o que deveria encarecer extraordinariamente a sua aquisição e conduziria, em certas ocasiões, à sua imitação.

Mas não seria apenas para embaratecer os custos que a ela se recorria. Seria também para falsificá-las. Plínio (Hist. Nat., Livro 37, 75) informa-nos de livros ou tratados em que se explica a maneira de dar ao vidro a cor das pedras transparentes (como a esmeralda, por exemplo). Reconhecendo, todavia, a existência de falsificadores e de negociantes sem escrúpulos, ele próprio dá uma série de conselhos práticos para reconhecer as pedras autênticas das imitações, o que deveria ser principalmente aplicado às gemas não gravadas.

Ainda hoje se torna difícil distinguir as gemas gravadas na Antiguidade das gravadas actualmente - as pedras então usadas eram praticamente as mesmas e os métodos de gravação praticamente iguais também. Além disso, as gemas permanecem inalteráveis com a idade e não adquirem patine nem incrustações. Apenas o vidro se torna irisado.

O fabrico de entalhes em pasta vítrea fazia-se vertendo o material 
fundido num molde ou pressionando-o, como se fosse cera, com um entalhe gravado em pedra. Para os colorir, adicionavam-se os corantes mais diversos ao material em fusão como, por exemplo, o manganês, que usado em quantidades adequadas, produzia o vidro incolor, o amarelo e o cor-de-vinho; ou o óxido de cobre ou o cobalto que podiam produzir o azul ou o verde.

A sua cronologia deverá, logicamente, corresponder à das pedras que pretendem imitar e que na época estariam em moda. Contudo, é opinião unânime entre os autores que se teriam iniciado na segunda metade do século I a. C. e teriam tido o seu auge em fins da República e durante a época de Augusto (época em que aparece um tipo determinado de pastas polícromas zonadas, de cores vivas: verde, branco e azul; e verde, negro e branco).

A substituição do vidro pela pedra vai-se generalizando no período de Júlio César, tornou-se popular durante a época de Augusto e continuou posteriormente. Todavia, ao longo da época imperial, quando se torna ainda mais comum o costume de usar anéis, continuam a fazer-se imitações, já que as pedras preciosas e semipreciosas não estavam ao alcance de qualquer um.

\section{Datação:}

A ausência de contexto arqueológico e de elementos gravados que permitam uma análise estilística e temática dificultam uma datação precisa. Todavia, seguindo a cronologia proposta pelos diversos autores para as peças em pasta vítrea e atendendo às suas grandes dimensões, poderemos datá-la de finais da República. Isto apesar de à pasta vítrea se recorrer, mesmo no período imperial, sempre que as condições económicas a isso obrigavam e de, por outro lado, se ter registado também um aumento de tamanho das pedras de anel, durante o Império, chegando a atingir grandes dimensões a partir do século III d. C. Contudo, as faces das pedras imperiais são planas (como as das gemas gnósticas ) enquanto as da pedra em questão são convexas.

\section{As minimáscaras de terracota}

Não são as únicas até agora encontradas no concelho de Cascais. Da villa do Alto do Cidreira provém uma outra, aliás em muito melhor 
estado de conservação, representando um negro e que foi pormenorizadamente estudada por Jeannette Nolen $\left({ }^{10}\right)$.

Nas de Freiría, porém, a fragmentação e/ou o desgaste são a tónica comum. Daí, as dificuldades no seu estudo e no estabelecimento de paralelos.

2.1. MÁSCARA N. ${ }^{\circ} 1$ - É de todas a mais pequena, desgastada e incompleta (Figs. 4 e 5).

\section{Descrição:}

- achada no estrato 4 do quadrado IIT

- número de inventário - 338

- Dimensões:

- altura máxima preservada - $41 \mathrm{~mm}$

- largura máxima preservada - $32 \mathrm{~mm}$

- largura da face $-25 \mathrm{~mm}$.

- Pasta:

- barro vermelho-alaranjado, com pequenas bolhas de ar

- elementos não plásticos:

- mica finíssima, branca

- quartzo hialino, leitoso e defumado

- minúsculos elementos de hematite e de feldspato.

- Cor: vermelho-alaranjado.

- Figura representada: dada a pequenez do fragmento e o seu desgaste, apenas se consegue vislumbrar parte do pescoço, o queixo e o nariz.

Corresponderá à face de uma cabeça inteira ou à parte frontal de um applique?

- Localização: na posse de Guilherme Cardoso.

\section{Datação:}

A pequenez do fragmento e o seu desgaste tornam, naturalmente, difícil o estabelecimento da sua cronologia. Todavia, o contexto ar-

$\left({ }^{10}\right)$ Vide: Nolen, Jeannette Srnit, "A Villa Romana do Alto do Cidreira - os Materiais", Separata do vol. XXVII (1988) de Conimbriga. Edição especial da Associação Cultural de Cascais. Coimbra, 1990. 
queológico é do século IV d. C. - período em que a actividade da villa foi ainda intensa (como o testemunham estruturas e materiais, nomeadamente, moedas). Poderemos datá-la desse século?

2.2. MÁSCARA N. ${ }^{\circ} 2$ - Apesar de ser a de maiores dimensões, está fragmentada, desgastada e incompleta (Figs. 6 e 7).

\section{Descrição:}

- achada no estrato 2 do quadrado TF

- número de inventário - 83

- Dimensões:

- altura total - $63 \mathrm{~mm}$

- largura total - $44 \mathrm{~mm}$

- largura da face - $32 \mathrm{~mm}$

- altura da face:

- do queixo ao pescoço - $35 \mathrm{~mm}$

- do pescoço ao cabelo - $40 \mathrm{~mm}$

- largura no sentido ântero-posterior (da nuca ao nariz) - $52 \mathrm{~mm}$.

- Pasta:

- barro castanho-claro, bastante friável e mole

- elementos não plásticos:

- quartzo hialino, defumado e leitoso (este em pequena quantidade)

- mica fina

- óxidos de ferro vermelhos, em pequena quantidade.

- Cor: castanho-claro.

- Figura representada: podemos garantir tratar-se de uma cabeça inteira, que seria trabalhada na face e na nuca. $\mathrm{Na}$ nuca, parece ver-se o penteado - talvez de risco ao meio e cabelos levemente ondulados, a emoldurar o rosto. Na parte frontal, apenas ressalta o pescoço fino e o queixo. Todo o resto é difícil de identificar, quer devido à fragmentação quer ao desgaste.

- Localização: na posse de Guilherme Cardoso.

\section{Datação:}

Tal como a anterior e embora mais completa, a fragmentação e o desgaste também não permitem o estabelecimento de uma cronologia 
segura. O penteado, se fosse mais nítido, ajudaria à sua datação, dado ser sempre um elemento importante no estudo da escultura romana.

2.3. MÁSCARA N. ${ }^{\circ} 3$ - É a única cuja face está completa, apesar de muito desgastada (Figs. 8 e 9).

\section{Descrição:}

- achada no estrato 5 do quadrado IV"

- número de inventário - 279

- Dimensões:

- altura total - $61 \mathrm{~mm}$

- altura da face (do queixo ao cabelo) - $39 \mathrm{~mm}$

- largura total - $39 \mathrm{~mm}$

- largura da face - $28 \mathrm{~mm}$

- Pasta:

- rosa, de cerne castanho-claro, com fendas e bolhas de ar; fractura em escama.

- elementos não plásticos:

- mica fina

- quartzo leitoso

- óxidos de ferro vermelhos, em grande quantidade.

- Cor: rosada.

- Figura representada: é trabalhada apenas na face, sem tratamento da nuca. Dado este facto, poderá pensar-se estarmos em presença de um applique ou peça de suspensão. Todavia, não há nela qualquer orifício que pudesse permitir fixá-la ou suspendê-la, como se verifica na referida máscara de negro do Alto do Cidreira. $O$ pescoço não se define claramente. Estaria envolto por um véu? No rosto arredondado, sobressai o queixo, já que o nariz, a boca e os olhos apenas se vislumbram. O penteado, de risco ao meio, emoldura o rosto, talvez em ligeiro ondulado, fazendo crer estarmos perante a representação de uma figura feminina. A ausência da nuca, porém, dificulta a sua identificação.

- Localização: na posse de Guilherme Cardoso.

\section{Datação:}

O desgaste e a ausência de tratamento da nuca tornam impossível a sua integração cronológica. 


\section{A lucerna}

Tal como a quase totalidade do material cerâmico desta villa (u), apareceu fragmentada. Um laborioso trabalho de restauro, executado por Severino Rodrigues, do Gabinete de Arqueologia da Câmara Municipal de Cascais, permitiu, porém, dar-lhe a forma que as figuras patenteiam (Figs. 10 e 11).

\section{Descrição:}

- Tipologia: Dressel 20

- Dimensões:

- comprimento máximo - 110,5 mm

- altura do corpo - 33,5 mm

- altura da asa - $56 \mathrm{~mm}$

- diâmetro do disco - 78 mm

- diâmetro da abertura do bico - $13 \mathrm{~mm}$.

- Pasta:

- pasta fina, bem classificada, apresentando grãos de dimensões apreciáveis (entre 2 e $3 \mathrm{~mm}$ ) de calcário e elementos ferruginosos; oxidante;

- cozedura inicial fortemente redutora, finalizada em atmosfera

- dureza acentuada (dificilmente riscada pela unha), devido à alta temperatura atingida durante a cozedura.

- Cor: castanho-alaranjado, com manchas cinzentas. Parte do bico está bastante enegrecida, o que nos permite concluir ter tido uma intensa utilização.

- Marca: não possui marca de oleiro, mas apresenta na base um $\mathrm{S}$, feito por incisão.

- Base: plana, com anéis concêntricos gravados.

- Asa: estriada (três estrias).

- Posição da asa: sobreposterior.

- Decoração: no disco, uma Vitória alada representada a três quartos, segurando uma palma na mão esquerda e erguendo uma coroa na mão direita. O pé esquerdo está apoiado sobre um globo (simbo-

(M) A única excepção é um vaso encontrado na campanha arqueológica de 1994, contendo o esqueleto completo de uma galinha. Tratar-se-á de um ritual de fundação? 
lizando o Mundo). Rodeando a cena, um cordão de pérolas, contornado, por sua vez, por folhagem em chevron.

É um tipo de decoração muito frequente em lucernas do século I d. C. e muito divulgado na época de Augusto. Em Portugal, o tema é também abundante. Sobretudo em Conimbriga, onde predomina. Delas nos dão notícia Ferreira de Almeida e o Professor Bairrão Oleiro (numa fase em que ainda faziam parte do acervo do Museu Nacional Machado de Castro) e Claudette Belchior. Mas em nenhuma das lucernas publicadas se encontra cena exactamente igual à de Freiría (12).

- Outros elementos:

- na região em que o rostrum arranca do disco, há uma pequena superfície onde se encontram dois pontos ligados por um traço - talvez reminiscências das formas de volutas do século $\mathbf{I}$ d. C.;

- a asa foi aplicada posteriormente, mas o orifício para a sua aplicação foi feito de uma maneira um tanto tosca.

- atendendo à textura, à pasta e ao tipo de cozedura, pode concluir-se não ser uma peça original, mas cópia de uma outra lucerna, provavelmente produzida em fornos do Tejo e do Sado.

- Localização: Gabinete de Arqueologia da Câmara Municipal de Cascais.

Datação: século III d. C.

\section{Agradecimentos:}

Não poderia deixar de manifestar a minha gratidão ao Doutor Bairrão Oleiro (que tive o privilégio de ter como professor, durante a licenciatura e, posteriormente, durante o mestrado e sob cuja orientação fiz a minha primeira campanha de escavações), a Guilherme Cardoso, a Severino Rodrigues, ao Professor José d'Encarnaçâo, ao Dr. Rebelo (dos Serviços Geológicos de Portugal) e a especialistas em Ourivesaria e Numismática do Museu Nacional de Arqueologia.

(12) Vide: AlmeidA, José António Ferreira de, "Introdução ao Estudo das Lucernas Romanas em Portugal”, Arqueólogo Português, n. s., II. Lisboa, 1953; BELCHIOR, Claudette, Lucernas Romanas de Conimbriga, Museu Monográfico de Conimbriga, 1969; OLEIRo, J. M. Bairrão, Catálogo de Lucernas Romanas, Museu Machado de Castro, Coimbra, 1952. 


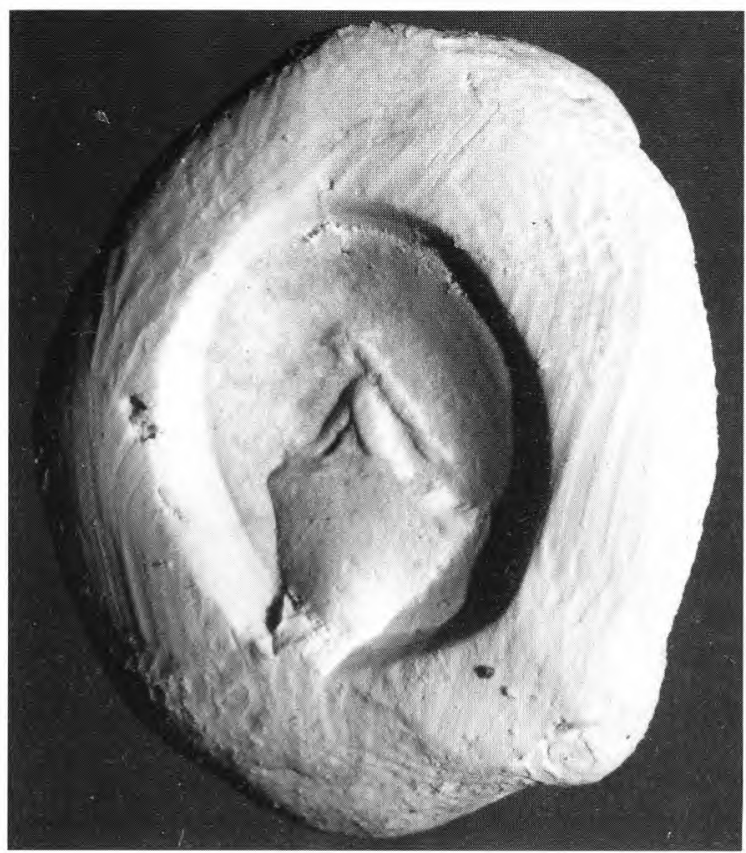

FIG. 1

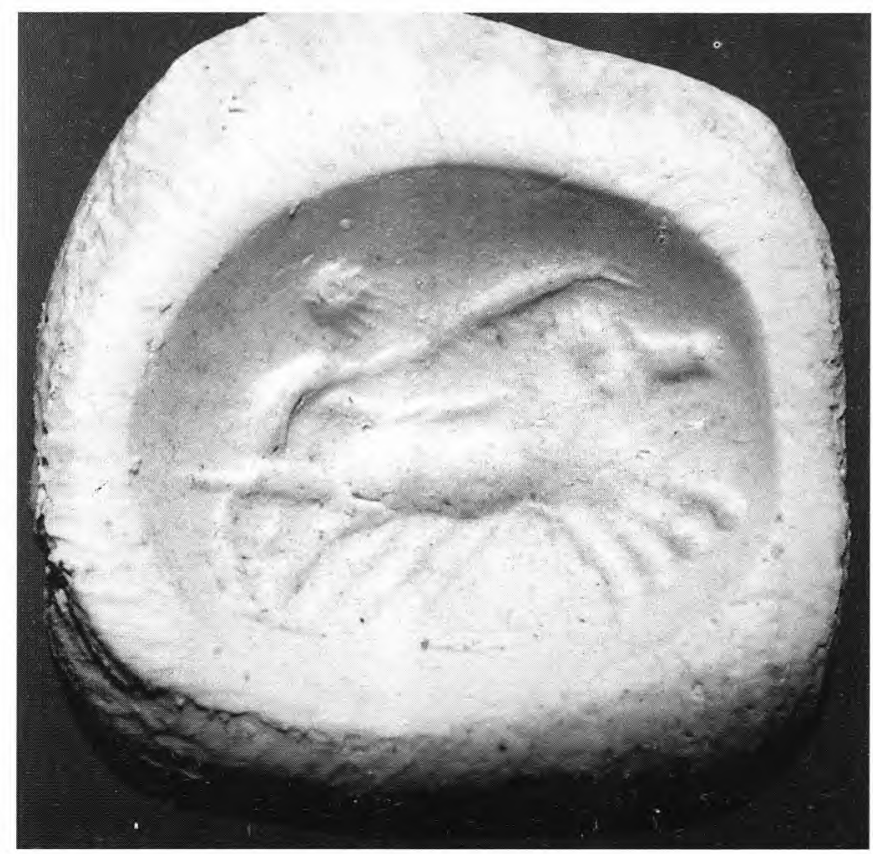

FIG. 2 


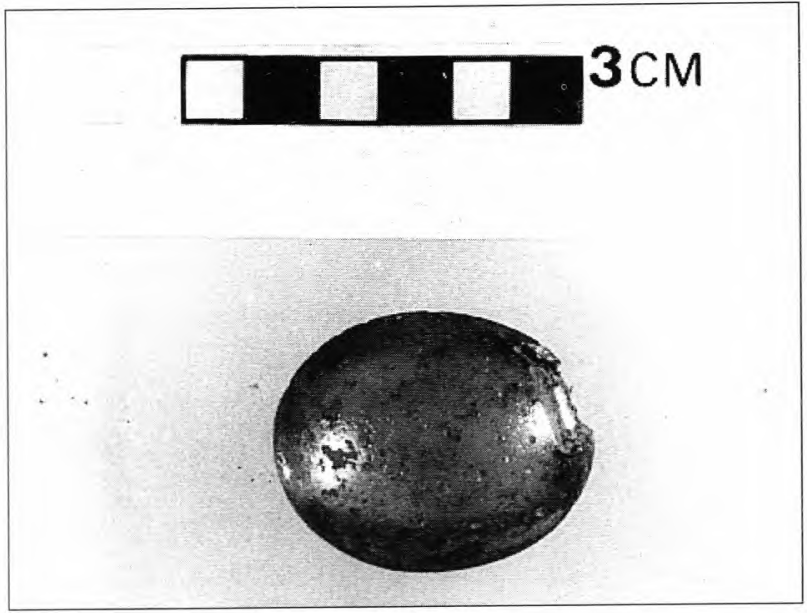

FIG. 3

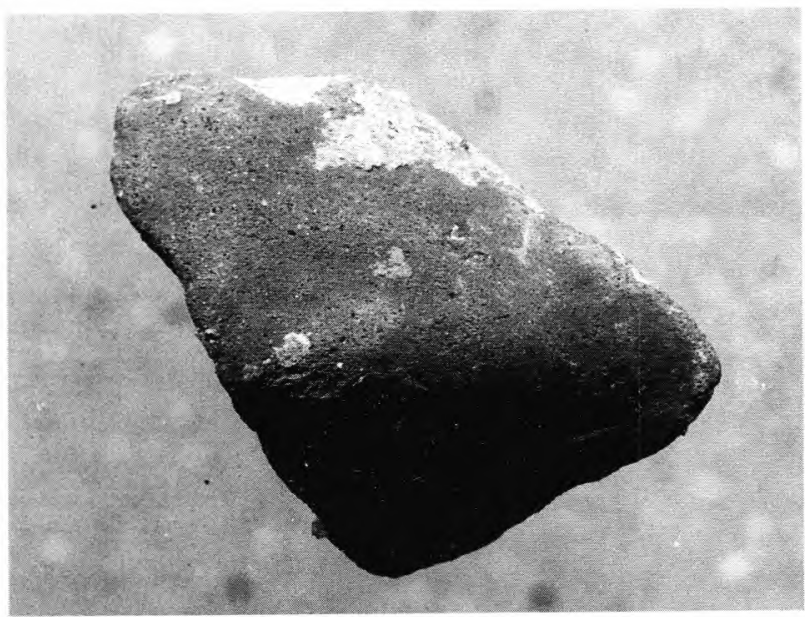

FIG. 4

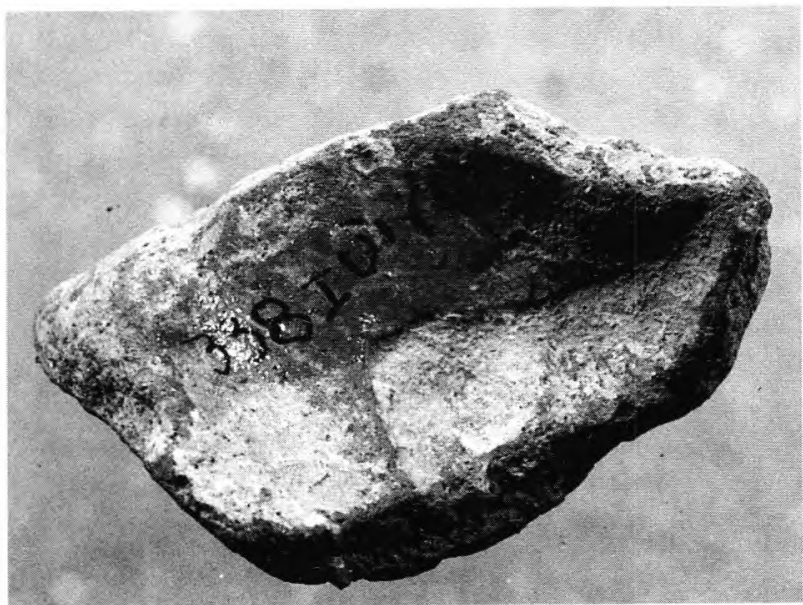

FIG. 5 


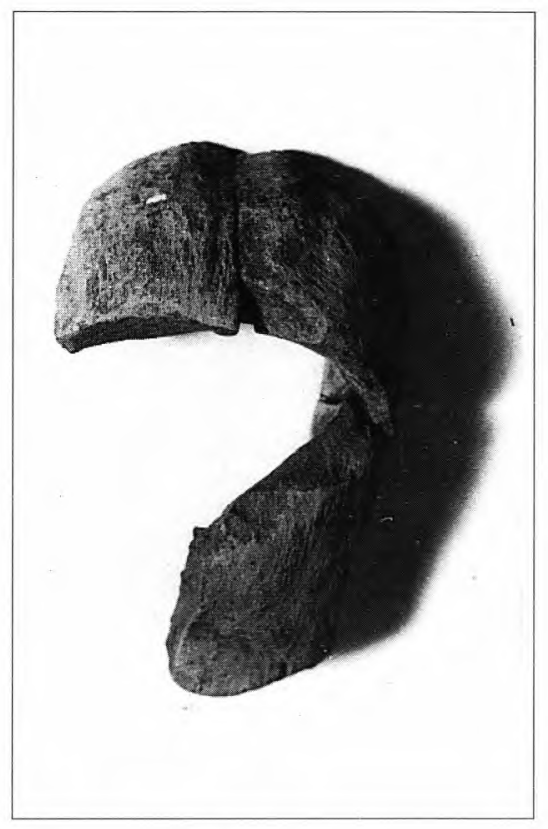

FIG. 6

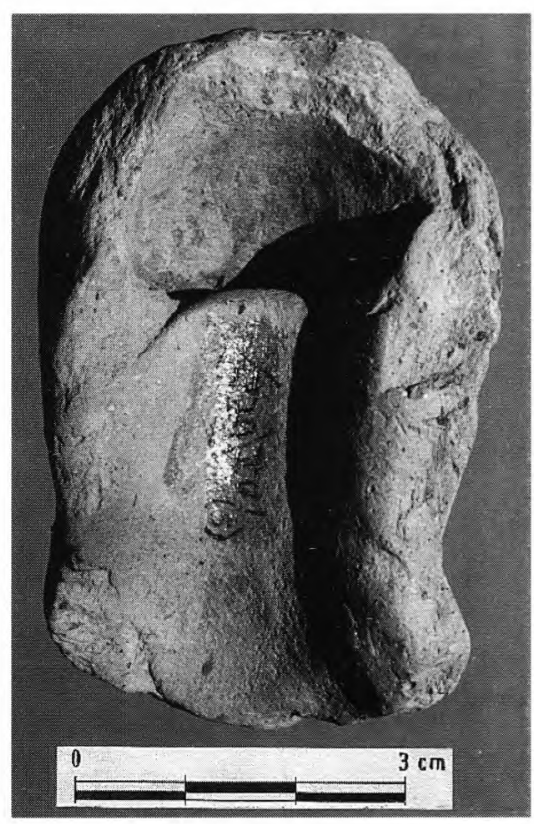

FIG. 8

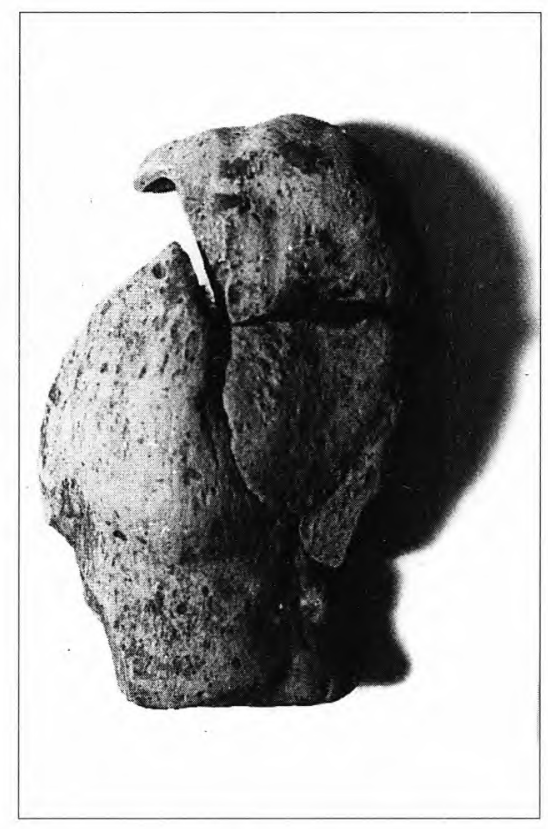

FIG. 7

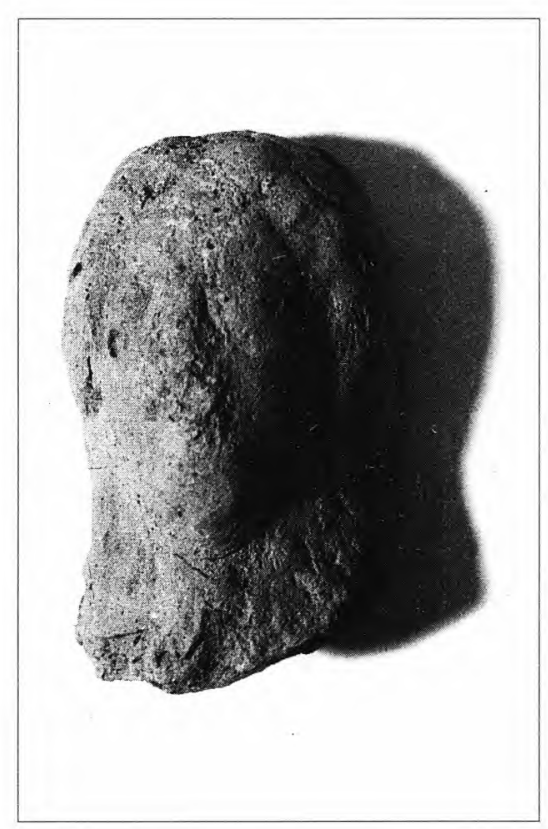

FIG. 9 


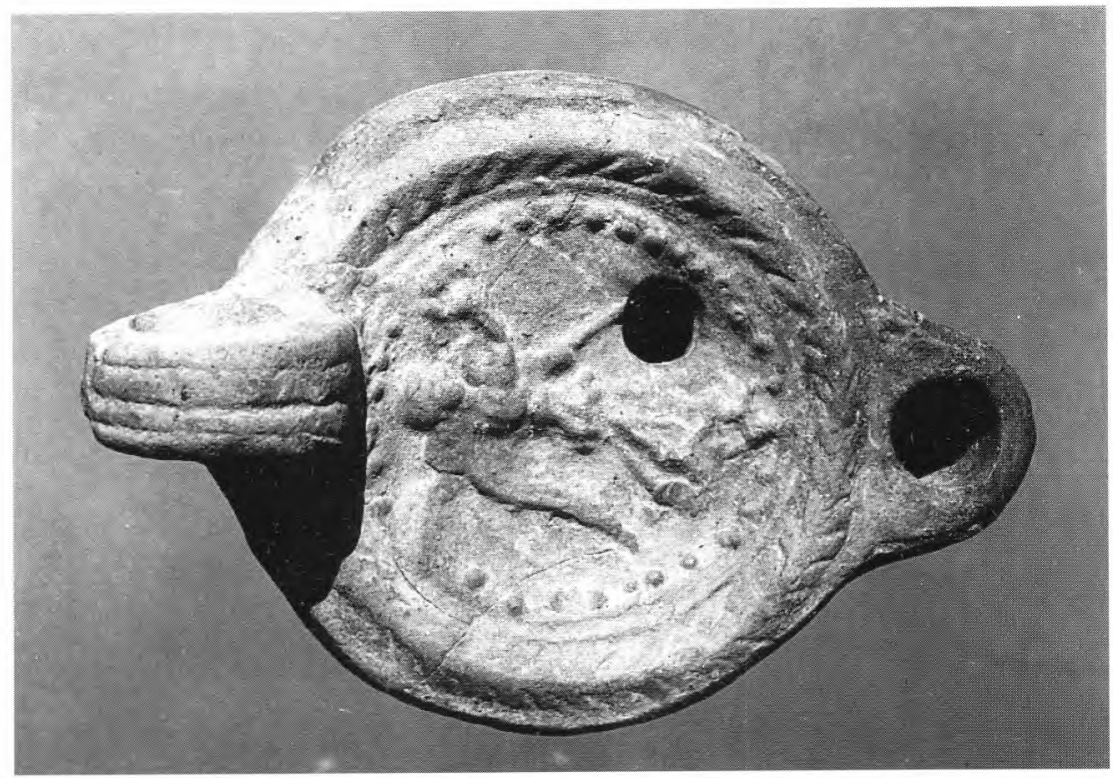

FIG. 10

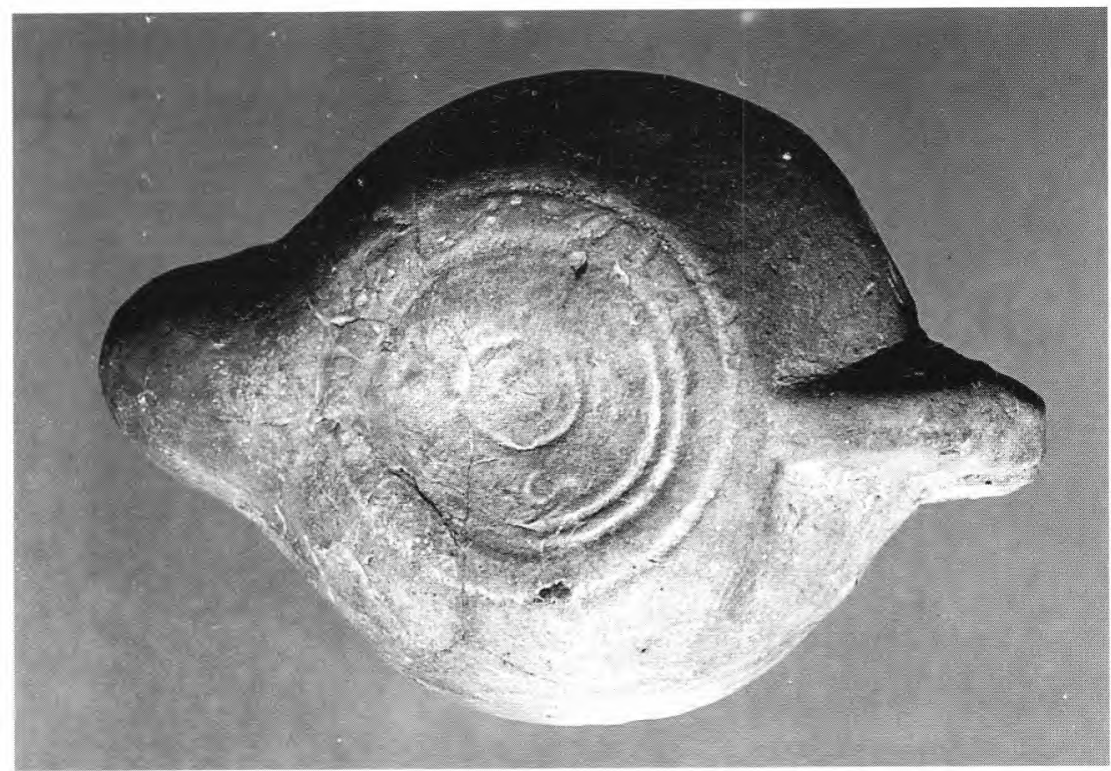

FIG. 11 